\title{
Sudden Death in Hemodialysis: An Update
}

\author{
Mehmet Kanbay ${ }^{a}$ Baris Afsar ${ }^{b}$ David Goldsmith ${ }^{c}$ Adrian Covic $^{d}$ \\ Department of Internal Medicine, Section of Nephrology, a Fatih University School of Medicine and ${ }^{b}$ Gulhane \\ Military School of Medicine, Ankara, Turkey; ' Department of Internal Medicine, Renal Unit, Guy's Hospital, London, \\ UK; ${ }^{d}$ Department of Nephrology Clinic and Dialysis and Transplantation Center, 'C.I. Parhon' University Hospital, \\ lasi, Romania
}

\section{Key Words}

Sudden death $\cdot$ Hemodialysis

\begin{abstract}
Cardiovascular disease including sudden death, myocardial infarction, cardiac arrest, malignant arrhythmias and other cardiac causes is the major cause of death accounting for $43 \%$ of all-cause mortality among hemodialysis patients. In addition to increased traditional risk factors, hemodialysis patients also have a number of nontraditional cardiovascular risk factors, which may play a prominent role in the development of sudden death such as left ventricular hypertrophy, coronary artery disease, rapid electrolyte shifts, QT dispersion, sympathetic overactivity, calcium-phosphate deposition. The purpose of the present review was to critically review the current literature to summarize the following aspects: (1) the pathophysiological mechanism responsible for sudden death in hemodialysis patients, and (2) the prevention and management of sudden death in hemodialysis patients.

Copyright $\odot 2010$ S. Karger AG, Basel
\end{abstract}

\section{Introduction}

Dialysis patients have extraordinarily high mortality rates. Cardiac disease is the major cause of death accounting for $43 \%$ of all-cause mortality among patients receiving hemodialysis (HD) and peritoneal dialysis (PD) $[1,2]$. In renal disease patients who are maintained on $\mathrm{HD}$, the death rate for cardiac arrest exceeds that for sepsis, pulmonary infection, stroke, and malignancy combined [1, 2]. In the United States Renal Data System (USRDS) database, the single largest cause of death is attributed to arrhythmic mechanisms and $61 \%$ of all cardiac deaths (or $27 \%$ of all-cause mortality) among HD patients are due to cardiac arrest/cause unknown or arrhythmia [3]. It has long been known that sudden death (SD) accounts for the majority of deaths in dialysis patients, particularly in diabetics, and SD was also identified as one of the most frequent causes of death in two national random samples of dialysis patients $[4,5]$. Cardiac arrest, which is a major cause of SD in chronic dialysis patients, is an event characterized by extremely high short-term mortality [6]. Karnik et al. [7] reported that the 48-hour mortality rate of 400 dialysis patients with cardiac arrest was $60 \%$. Additionally, Moss et al. [8] reported that cardiopulmonary resuscitation in dialysis patients has been associated with

Mehmet Kanbay, MD

Alparslan Mahallesi

Umit sokak, No. 25/14

Melikgazi, Kayseri (Turkey)

Tel. +90 505266 8866, Fax +90 312441 5498, E-Mail drkanbay@yahoo.com 
Fig. 1. Possible causes of sudden death in dialysis patients.

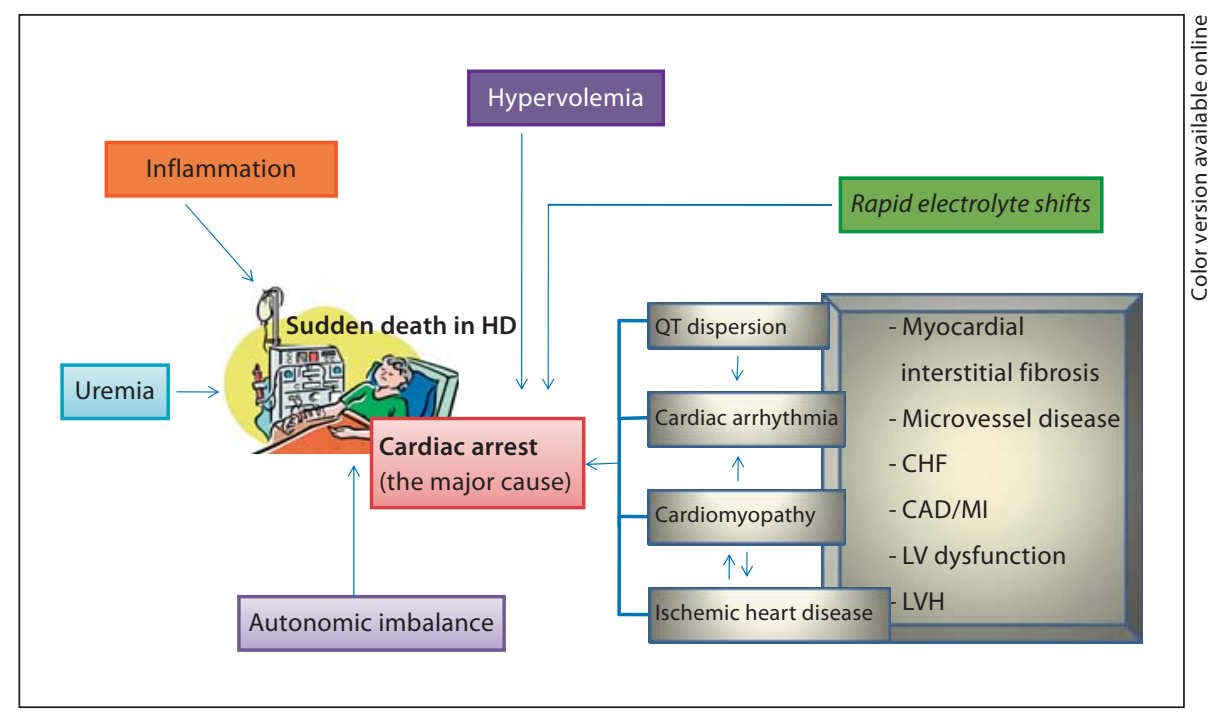

very poor survival with $92 \%$ in-hospital deaths, and $97 \%$ 6-month mortality. The purpose of this review was to critically review the current literature examining the causes and prevention of SD in HD patients.

\section{Definition of SD}

There is no universally accepted definition for SD. However, it can be defined as unexpected natural death within a short time period generally $\leq 1 \mathrm{~h}$ from the onset of symptoms, in a person without any prior condition that would appear fatal. Another definition is that SD is an unexpected natural death due to cardiac etiology preceded by a sudden loss of consciousness [9]. In one study, $\mathrm{SD}$ was defined as unexpected natural death that occurred within $24 \mathrm{~h}$ of new or more serious symptoms or during sleep or while unobserved [10].

\section{Possible Mechanisms Responsible for SD in HD}

The recognized risk factors for SD described in the general population are also present in HD patients. Cardiomyopathy and ischemic heart disease including acute myocardial infarctions, which are both common conditions in dialysis patients, likely play a role in the development of SD. After percutaneous and surgical coronary revascularization, dialysis patients are still remaining at a high risk for sudden cardiac death [6]. The 4D study which was a prospective randomized controlled study by
Wanner et al. [11] disclosed that although atorvastatin reduced LDL-cholesterol, primary end points (comprising death from cardiac causes, fatal stroke, nonfatal myocardial infarction, or nonfatal stroke) were reduced by only $8 \%$ and were not statistically significant $(\mathrm{p}=0.37)$. The main post-hoc explanation for the negative outcome of the $4 \mathrm{D}$ study is the fact that adjudicated death from coronary heart disease accounted for only $9 \%$ of deaths, while other cardiac causes accounted for 35\% among these, SD was the most frequent [12]. These findings imply that other unique factors may contribute to the increased risk of sudden cardiac death in end-stage renal disease (ESRD) patients (fig. 1).

\section{Left Ventricular Hypertrophy and Heart Failure}

Left ventricular hypertrophy (LVH) is almost invariably present and both concentric and eccentric LVH are frequently seen in HD patients. In experimental models, it has been shown that LVH occurs even in the absence of hemodynamic stimuli (increased preload and/or afterload) suggesting an inappropriate hypertrophic remodeling process of the heart [13]. It is well demonstrated that $\mathrm{LVH}$ is an independent powerful indicator of mortality in dialysis patients and the presence of $\mathrm{LVH}$ is also an important determinant of the development of arrhythmia in dialysis patients [14]. Moreover, previous studies showed that heart failure and systolic dysfunction was frequent in dialysis patients and these patients had the worst survival prognosis [15]. In one study, older age and left ventricular systolic dysfunction were identified as independent determinants of development of arrhythmia 
in patients who were on renal replacement therapy [16]. Analysis of Holter recordings by Tamura et al. [17] revealed that Lown class 4A-type and B-type ventricular arrhythmia was noted in $17 \%$ of the uremic patients in whom left ventricular systolic dysfunction, age, and male sex were associated with development of arrhythmia. In the light of these findings, $\mathrm{LVH}$ and heart failure (especially as a form of systolic dysfunction) by inducing cardiac arrhythmias may lead to SD. However, today it is not exactly known to what degree these risk factors predict $\mathrm{SD}$ in dialysis patients [12].

\section{Presence of Myocardial Interstitial Fibrosis and Microvessel Disease}

It is well known that fibrosis promotes arrhythmia. If fibrous tissue with high electrical resistance is interposed between myocytes, it will cause local delay in the spread of action potential favoring the development of atrial and ventricular reentry types of arrhythmias [18]. Another unique abnormality of cardiac structure in uremia is microvessel disease and capillary deficit (capillary/myocyte mismatch). This results from inadequate capillary growth in response to cardiac hypertrophy despite increased expression of vascular endothelial growth factor [19]. Inadequate capillary density will restrict the ability of the heart to cope with increased oxygen demand and may result in relative hypoxia, a risk factor for the development of arrhythmias especially during the dialysis procedure [12]. Furthermore, coronary artery disease which is very common in ESRD patients with or without previous myocardial infarction might be a triggering factor for $\mathrm{SD}$.

\section{Rapid Electrolyte Shifts and Hypervolemia}

SD in dialysis patients is both frequent at hours after the start of dialysis and during the hours preceding the next dialysis session. Furthermore, SD is particularly frequent after the long interdialytic period [7, 20, 21]. These findings imply that rapid electrolyte shifts and hypervolemia might be triggering factors for SD. Whether nocturnal dialysis or long, slow dialysis will reduce the incidence of SD needs further investigation.

\section{QT Dispersion}

QT dispersion is defined as the difference between the longest and shortest QT intervals for a given set of complete 12 electrocardiograms. It has been proposed as a noninvasive electrocardiographic parameter that might predict an increased risk of malignant arrhythmias [22]. Dialysis patients have prolonged QT interval and QT dispersion [23]. A single session of HD might further in- crease QT dispersion in both adults and children [24, 25]. Dialysis patients with QT dispersion longer than $74 \mathrm{~ms}$ were shown to be at risk for serious ventricular arrhythmias or SD [26]. Recently, it was suggested that acquired long QT syndrome may be one of the triggering event for $\mathrm{SD}$. Acquired long QT syndrome manifests itself by both decreased $\mathrm{K}^{+}$-channels (thus diminishing repolarization reserve) and by increased sensitivity of the remaining $\mathrm{K}^{+}$channels to inhibition [27]. Genovesi et al. [28] investigated the effect of different combinations of potassium and calcium concentrations on QT interval in the dialysis bath in dialysis patients. They found that the combination of low potassium and low calcium concentration in the dialysate is associated with the longest QT values during and immediately after the HD session, whereas with high potassium and calcium concentration the reverse is true, as the shortest QT interval values were observed during this condition. There is also a genetic variant of long QT syndrome. The dialysis sessions can trigger SD in dialysis patients with an unrecognized genetic variant of long QT syndrome. These patients are characterized by dysfunction of ion channels, so-called channelopathy [29].

\section{Sympathetic Overactivity}

It was previously shown that sympathetic overactivity is an established indicator of cardiac risk. The plasma norepinephrine concentration is a predictor of death and cardiovascular events in dialysis patients without congestive heart failure [30]. The sympathetic nervous system by acting through $\beta_{1}$ and $\beta_{2}$ receptors can increase the heart rate which not only adversely affects the relation between myocardial demand and supply, but can also induce cardiac hypertrophy and fibrosis which are suspected to be risk factors for sudden cardiac death [31]. In addition, heart rate variability (reflecting autonomic dysfunction) and altered baroreflex sensitivity or sensitivity index, respectively (an index of baroreflex dysfunction) were considered to be risk factors for SD. Heart rate variability (HRV) can be defined as the oscillation in the interval between consecutive heart rates, rather than the heart rate per se, as well as the oscillation in the interval between consecutive instantaneous heart rates. A reduction in HRV can be interpreted as a tip in the balance toward a decreased vagal tone and as a result subsequent to increased (unopposed) sympathetic tone [32, 33]. Decreased HRV is frequently seen in dialysis patients. Hayano et al. [10] reported that decreased HRV has an independent prognostic value in chronic HD patients and identifies an increased risk for all-cause and SD. It was 
hypothesized that increasing the frequency and duration of HD would provide a more physiologic homeostasis that will lead to a more normal sympathovagal balance and decrease incidence of sudden cardiac death. A small cohort study by Chan et al. [34] on ESRD patients assessed whether nocturnal HD would lower the sympathetic drive, as measured by HRV, during sleep and that this decrease would be associated with an improvement in nocturnal hypoxemia. It was found that the apnea-hypopnea index, nocturnal hypoxemia and RR interval were significantly higher in the dialysis population on conventional HD (4 h, three times per week) as compared to the control population. However, after they were converted to nocturnal HD (8-10 h, six times per week) decreases in the apnea-hypopnea index, nocturnal hypoxemia and a fall in heart rate were noted. However, at this point there are insufficient data showing that normalization of HRV would improve clinical outcomes and patient survival in the ESRD population [9].

\section{Role of Hypertension}

Hypertension is another cause of arrhythmia in uremic patients. De Lima et al. [35] found that hypertension and coronary artery disease are the most important determinants of complex ventricular arrhythmia in ESRD patients. Another study reported that hypertension together with diabetes mellitus and advanced age is the predictor of arrhythmia in uremic patients [36]. Hypertension was thought to induce arrhythmia by causing mechanical stress and provoking ischemia, especially in the presence of LVH or myocardial fibrosis. Presence of hypertension itself not only induces ventricular hypertrophy, but also induces cardiac fibrosis which are both risk factors for sudden cardiac death [12]. Bozbas et al. [37] showed that hypertension is one of the independent predictor of complex ventricular arrhythmia in maintaining HD patients.

\section{Role of the Renin-Angiotensin-Aldosterone System}

In animal studies, overexpression of angiotensin II was found to be responsible for SD [38]. Also, in ESRD patients polymorphisms of the renin-angiotensin system genes were found to be associated with QTc interval prolongation which leads to fatal arrhythmias [39]. In humans, direct evidence is lacking and conflicting results were reported [40, 41].

\section{Calcium/Phosphorus Deposition}

Deposition of calcium and phosphorus in interstitial space and in the walls of intramyocardial arteries might be one of the mechanisms. It is also hypothesized that hyperphosphatemia affects intracellular handling of calcium and thus interferes with electrical stability [12]. Calcium-phosphate precipitates are among the factors causing abnormal conduction and late potentials formation in ESRD patients [37]. Two large national studies identified high predialysis serum phosphate not only as a powerful predictor of coronary death but specifically also of SD, the relative risk being 1.06 compared with 1.08 for coronary artery disease and cerebrovascular accident [5]. The influence of secondary and tertiary hyperparathyroidism as a risk factor for the syndrome of SD is not studied in dialysis patients. Also, whether the rate of SD reduced following subtotal parathyroidectomies needs evaluation.

\section{Inflammatory State}

Despite the frequency of SD in dialysis patients, few studies have prospectively measured the association between SD and inflammation. In a large prospective study including 1,041 incident dialysis patients, Parekh et al. [42] demonstrated that SD is associated with inflammation and malnutrition as determined by low serum albumin and higher high-sensitive C-reactive protein and interleukin-6 levels. These associations were direct and independent of traditional cardiovascular risk factors. The authors speculated that inflammation could trigger SD through atherosclerosis or direct effect on the myocardium and the electrical conduction system. This was a pioneering study and more studies are definitely needed to understand the pathophysiologic associations between $\mathrm{SD}$ and inflammation in dialysis patients.

\section{Other Factors}

Anemia, dyslipidemia, hyperhomocysteinemia, endothelial dysfunction, decreased perfusion reserve, diminished ischemia tolerance and acid-base disturbances are suspected to be other risk factors and they may all contribute to the heightened vulnerability to sudden cardiac death in dialysis patients [3, 7]. It is of note that the risk of SD in dialysis patients is not uniform and is not stable over time. The risk is related to patients' age and dialysis duration. In a USRDS cohort study of all incident US dialysis patients surviving at least 1 year after dialysis initiation, the rate of cardiac arrest progressively rose from 93 events per 1,000 patient years 2 years after dialysis initiation to 164 events per 1,000 patient years 5 years after dialysis initiation [43]. In 2002, period-prevalent dialysis patients receiving renal replacement therapy for 5 or more years had an estimated adjusted mortality rate of 
Fig. 2. Prevention of sudden death in dialysis patients.

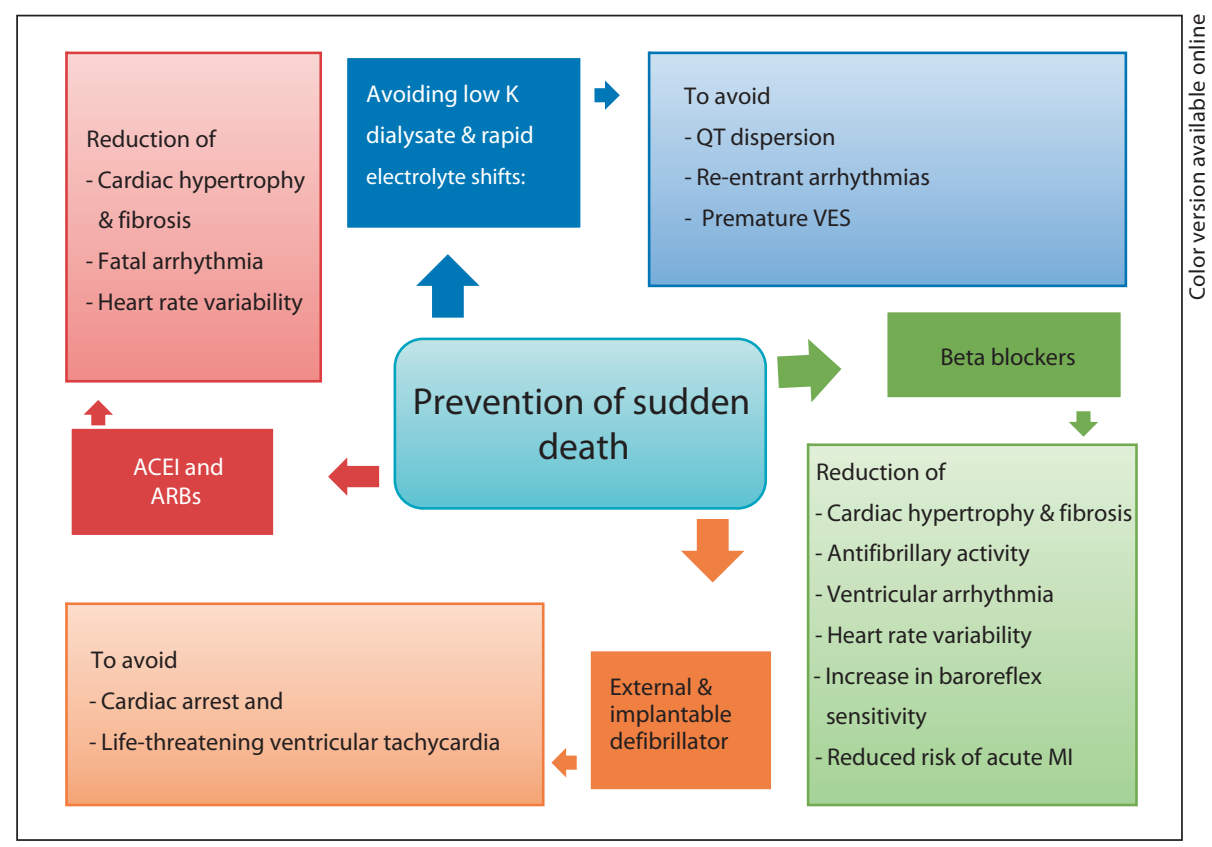

286 deaths per 1,000 patient years [44]. The probability of cardiac arrest is lower in the chronic kidney disease (CKD) population compared with those on dialysis, in whom the probability is $24 \%$ at 3 years [45]. These data support the notion that ESRD itself may be a triggering factor for cardiac disease and for SD. Of note, the nonphysiologic nature of conventional thrice-weekly HD sessions may further increase the risk of SD. An interesting study showed that frequency of sudden and cardiac death increased by $50 \%$ on Mondays for patients dialyzing Monday, Wednesday, and Friday, with similar trends on Tuesdays for patients dialyzing Tuesday, Thursday and Saturday [21]. A 3-fold increased risk of SD in the $12 \mathrm{~h}$ before the end of the long weekend interval, and a 1.7-fold increased risk of SD in the $12 \mathrm{~h}$ starting with the dialysis procedure following this long interval have also been demonstrated [20].

\section{Prevention of SD in Dialysis Patients}

Since the risk factors for SD in dialysis patients is not understood perfectly, prevention studies are relatively scarce. Additionally, nearly all clinical trials which used $\mathrm{SD}$ as an end point in dialysis patients are either excluded or subgroup analyses including dialysis patients were not made. However, this does not mean that dialysis patients will not benefit from therapeutic interventions and some suggested interventions are summarized below (fig. 2).

\section{Avoiding Low Potassium Dialysate and Rapid \\ Electrolyte Shifts}

Dialysis patients are at increased risk of SD especially during hemodialysis. In conventional HD with constant and low potassium (range $0-2.5 \mathrm{mEq} / \mathrm{l}$ ), a large amount of potassium is abruptly removed from the extracellular space [46]. Most of this potassium originates from the cells, crosses the cell membrane, the extracellular space (the blood) and the dialysis membrane before reaching the dialysate. The depletion of the potassium reserves within the cells may have important repercussions on cardiac electrophysiology. Potassium concentration gradient across the cell membrane is critical for the repolarization process, being responsible for both the resting and action potentials [47]. Potassium fluxes during HD have been associated with an increase in QT interval and an increase in the dispersion of QT [48-50]. The resulting repolarization heterogeneity allows for the onset of distinctive re-entrant arrhythmias, and hypokalemia may act as a triggering factor in the genesis of premature ventricular depolarizations and cardiac arrhythmias. In a retrospective study, Karnik et al. [7] found that patients who suffered a cardiac arrest at the time of dialysis were twice as likely to be dialyzed against a 0 or $1.0 \mathrm{mEq} / \mathrm{l}$ dialysate compared to controls despite no difference in pre- 
dialysis potassium levels. Bleyer et al. [20] reporting on SD in 88 hemodialysis patients found that $13 \%$ had serum potassium below $3.5 \mathrm{mEq} / \mathrm{l}$ and $\geq 6.0 \mathrm{mEq} / \mathrm{l}$ on routine prior monthly laboratory values. Floccari et al. [51] showed that an increase in QT dispersion - which is a risk factor for arrhythmias - during the first hour of HD when arrhythmias frequently occur, was inversely correlated with the rapid removal of potassium. Thus, avoiding rapid electrolyte shifts and dialysate very low in potassium is a sensible strategy to reduce the risk of cardiac arrest in hemodialysis centers but it is unlikely to eliminate the hazard [52]. It is recommended that the dialysate prescription be evaluated and modified on an ongoing basis [3]. Indeed, Santoro et al. [47] showed that a greater tendency for arrhythmogenic activity with the use of a constant and relatively low potassium concentration as compared to decreasing potassium profiling in dialysis-sensitive arrhythmic patients although the results were nonsignificant. They speculated that the low number of patients with serious arrhythmias during the study sessions, notwithstanding their selection on the grounds of the presence of intradialysis arrythmias, could be one of the explanations for the lack of evidence for significant differences on the statistical level. They suggest a smoother potassium removal may well engender a kind of protective effect.

\section{Beta-Adrenergic Blockers}

$\beta$-Blockers decrease SD by mechanisms beyond their effects on ischemia and include: antifibrillary activity, sympathoinhibitory effect, decrease in frequency of ventricular arrhythmia, improvement in HRV and increase in baroreflex sensitivity [53-56]. One can speculate that $\beta$-blockers, by their multiple effects, can reduce sympathetic activity and SD especially in high-risk populations. Indeed, data from several large clinical trials show attenuation of risk for SD with $\beta$-blockers in several high-risk patient population groups including hypertension, myocardial infarction, ischemic heart disease, heart failure and left ventricular dysfunction [6]. As mentioned above in dialysis patients overactivation of the sympathetic system is frequently seen [6]. In animal models of kidney disease, kidney damage is associated with increased afferent sympathetic activity $[57,58]$. Interestingly, after successful renal transplantation, removal of the recipient's own anuric kidneys normalized sympathetic nerve activity, which had remained elevated after transplantation, illustrating the role of the damaged kidney in triggering sympathetic overactivity [59]. In healthy persons, kidneys produce renalase which ca- tabolizes catecholamines [60]. Thus, it is probable that as kidney function diminishes, renalase also decreases, which in turn results in increased concentrations of catecholamines. Increased sympathetic activity has also been associated with the dialysis treatment per se [61]. Although all these factors were well demonstrated in dialysis patients surprisingly few studies were conducted to demonstrate the effect of $\beta$-blockers on dialysis patients. $\beta$-Blockers are not homogeneous but rather a heterogeneous group. Two important characteristic of $\beta$ blockers, i.e. cardioselectivity and lipophilicity, are important for their cardiac effects. For example, it was hypothesized that hydrophilic $\beta$-blockers may not be as effective in preventing sudden cardiac death as lipophilic $\beta$-blockers. Investigators suspected that lipophilic $\beta$ blockers could penetrate the central nervous system and indirectly mediate an increase in vagal tone that is of importance for the prevention of ventricular arrhythmias and SD [62]. Metabolism of a $\beta$-blockers is also an important concern. For example, among other $\beta$-blocking agents in renal disease patients, carvedilol is endowed with favorable kinetic characteristics in view of its prevalent hepatic metabolism that does not require dose adjustment in case of impaired renal function [63]. In addition, carvedilol exerts antioxidant effects that may further protect the heart from ischemia or reperfusion damage independent of its actions as an adrenoreceptor blocker [64]. It is uncertain that all $\beta$-blockers are equal in their action in dialysis patients. These issues were not satisfactorily evaluated in dialysis patients. One study examined the influence of $\beta$-blocker usage on the increased cardiovascular risk associated with CKD among a large cohort of male and female patients who are not on dialysis and with established coronary heart disease (CHD). They showed that $\beta$-blockers are associated with a reduced risk of acute myocardial infarction or sudden cardiac death in patients with CHD irrespective of kidney function when compared to CHD patients without kidney impairment and not receiving $\beta$-blockers. The relative reduction in the incidence of the primary endpoint by $\beta$-blockers was somewhat better for patients with relatively preserved kidney function. Furthermore, the observed relationship remained significant after multivariate analysis [65]. A study by Pun et al. [66] revealed that $\beta$-blockers increased the odds of surviving after cardiac arrest. They demonstrated that in 729 patients who were identified as having a confirmed incenter cardiac arrest, the 24-hour survival rate is only positively related with $\beta$-blocker usage after adjusting for covariates (OR 0.61, 95\% CI 0.44-0.86, $\mathrm{p}=0.005$ ). Fur- 
thermore, they found that prescription of $\beta$-blockers was consistently predictive of survival at time points as early as $24 \mathrm{~h}$ after an arrest. Examination of the medications that were prescribed to patients at the time of the event also yielded several significant differences at the 6-month time point. $\beta$-Blocker prescriptions again were more prevalent in the survivor group after adjusting for covariates (OR $0.32,95 \%$ CI $0.17-0.61, \mathrm{p}=0.0006)$. They also observed a decreasing odds of death with increasing medication dosage for $\beta$-blockers at the 6 -month time point. Cice at al. [67] randomized $114 \mathrm{HD}$ patients with dilated cardiomyopathy to receive carvedilol or placebo in a controlled study. Of note, all patients were either on angiotensin-converting enzyme inhibitors (ACEi) or angiotensin-receptor blockers (ARB) and were symptomatic for heart failure (New York Heart Association functional class II-III). After 12 months' treatment with carvedilol, there was a statistically significant improvement in the left ventricular ejection fraction (from 26 to $36 \%$ ). Then they followed the same patient population for an additional 12 -month period. After 2 years' follow-up, they demonstrated that $51.7 \%$ of the patients died in the carvedilol group compared to $73.2 \%$ in the placebo group $(\mathrm{p}<0.01)$. There were significantly fewer all-cardiovascular deaths ( 29.3 vs. $67.9 \%, \mathrm{p}<0.0001)$ among patients receiving carvedilol than among those receiving placebo. Furthermore, a reduction in SD was also observed (2 in the active treatment group and 6 in the placebo group) even if it did not reach statistical significance. The authors were aware of the fact that their sample size is limited and it was possible that in a larger patient population significant differences could be detected also in SD [68]. Although these results of $\beta$-blockers on chronic dialysis patients were encouraging, they are relatively underused in CKD patients. In a very recent paper, it was recommended that especially some $\beta$-blockers with approved indications for cardiovascular mortality benefit such as metoprolol and carvedilol should be more frequently used in CKD patients [69].

\section{Angiotensin-Converting Enzyme Inhibitors and}

Angiotensin-Type Receptor Blockers

Although the favorable effects of ACEi in patients without renal disease have been shown in multiple studies, the data about the use of ACEi in dialysis patients with heart failure or their effect on SD are scarce. Also, the effect of ACEi treatment may be different in specialized population groups (e.g. dialysis patients). For example, in one study it was reported that, in contrast to the general population, ACEi treatment reduced HRV in
ESRD patients. The authors of this study suggest that the risk versus benefit of ACEi use in patients with ESRD warrants further investigation [33]. In a retrospective study, Efrati et al. [70] reported a 52\% reduction in mortality among dialysis patients on ACE inhibitors despite no difference in blood pressure reduction. On the contrary, a prospective trial of fosinopril in dialysis patients did not demonstrate a significant difference in the rate of major cardiovascular events [40]. There is paucity of data related to the use of ARBs for the prevention of cardiac mortality in dialysis patients. A small randomized trial of candesartan in dialysis patients demonstrated an almost 3-fold reduction in cardiovascular events and a reduction in number of fatal arrhythmias. However, the significance of the latter finding is limited by the small number of events [41]. In patients with a history of cardiac arrest, Pun et al. [66] demonstrated that the use of ACEi/ARBs was associated with better survival at 6 months after adjusting for various covariates (OR 0.51, 95\% CI 0.28-0.95, $\mathrm{p}=0.03$ ).

There is no doubt that larger trials will be necessary before any strong conclusions on the use of ACE inhibitors or $\mathrm{ARBs}$ to prevent $\mathrm{SD}$ in $\mathrm{HD}$ patients can be made.

\section{External Defibrillators and Implantable Cardioverter Defibrillators}

The National Kidney Foundation Dialysis Outcome Quality Initiative Clinical Practice Guidelines for Cardiovascular Disease in Dialysis Patients recommends basic life support training for dialysis staff and on-site capability for external cardiac defibrillation either with an autonomic external defibrillator or standard manual defibrillator [71]. Lehrich et al. [72] in a retrospective multicenter study showed that unadjusted survival at 30 days was 19 versus $15 \%(p=0.12)$ and 9.5 versus $7.8 \%$ $(\mathrm{p}=0.39)$ in the automated external defibrillator (AED)present and AED-absent groups, respectively. Of the 237 patients who experienced cardiac arrest in centers with AEDs on-site, $53 \%$ were receiving $\beta$-blockers compared with $41.8 \%$ of 492 patients at non-AED sites ( $\mathrm{p}=0.01$ ). After controlling for case mix and confounders including medical therapy, AED presence was not associated with improved outcome of survival from cardiac arrest (hazard ratio $0.98 ; 95 \%$ CI $0.82-1.18 ; \mathrm{p}=0.83$ ). They concluded that one year survival from cardiac arrest was not improved in clinics with AED compared with those without AED even after adjusting for confounding variables. The data in the literature about the usage and benefit of implantable cardioverter defibrillators (ICD) are not satisfactory. In the general population, ICDs have 
been shown to be superior to medical therapy for improving the outcome of survivors of cardiac arrest and life-threatening ventricular tachycardia [73]. Prospective clinical trials are scarce for the primary prevention of sudden cardiac deaths in dialysis patients and the majority of the ICD trials have excluded patients with CKD [74-79].

Some authors fear the fact that comorbid conditions which are highly prevalent in dialysis patients may reduce the benefit from ICD implantation in this population. Indeed, it is well known that a very low percentage of dialysis patients were receiving the ICD device. There are several plausible explanations for the apparent underutilization of ICDs in dialysis patients. It is plausible that concerns regarding potential complications (e.g. infection, difficulties with vascular access) might dissuade clinicians from ICD implantation.

Indeed, several series have shown a lack of efficacy of an ICD in patients with advanced renal failure, in terms of increased mortality and lower survival, questioning whether the potential benefit from the ICD is negated by the setting of ESRD with high mortality from comorbidities [80-82]. Dasgupta et al. [83] reported in a retrospective study that patients with ESRD had greater complication rates after peacemaker or ICD implantation compared with matched controls. In their study, $23 \mathrm{com}$ plications occurred in 16 of 41 patients with ESRD (39\%) versus 13 complications occurred in 13 of 123 matched controls $(11 \%)(\mathrm{p}<0.001)$. Major complications occurred in $29 \%$ of patients with ESRD versus $5 \%$ controls $(\mathrm{p}<$ 0.001 ), whereas minor complications occurred in 17 and $6 \%$, respectively $(\mathrm{p}<0.03)$. In their logistic regression analysis, ESRD was found to be a strong predictor of complications (OR 5.4, 95\% CI 2.3-12.7, p < 0.0001). Furthermore, they suggest that patients with advanced kidney disease may be less responsive to ICD therapy, possibly resulting from higher defibrillation thresholds. Amin et al. [84] reported that the mortality benefit from primary prevention ICD implantation hinges largely on the patient's age and stage of kidney disease. They found that with stages 1 and 2 CKD, ICD implantation reduces mortality. However, in patients with more advanced stages of $\mathrm{CKD}$, the benefit is less significant and age dependent. This is attributed to patients with advanced CKD having a higher procedural risk and decreased life expectancy. With average procedural mortality, ICD implantation is favored at ages $<80$ for stage 3 , ages $<75$ for stage 4 , and ages $<65$ for stage 5 . As procedural mortality rates increase, age thresholds for ICD implantation decrease. In one retrospective study, patients who underwent ICD im- plantation for primary prevention of SD were stratified by CKD, defined as serum creatinine $\geq 2 \mathrm{mg} / \mathrm{dl}$ or dialysis use. Primary endpoint was mortality. There were 33 deaths during a follow-up period of $18.0 \pm 15.2$ months: 17 of 35 CKD patients and 16 of 194 patients without CKD (48.6 vs. $8.2 \%, p<0.00001$ by log-rank). One-year survival for patients with and without CKD was 61.2 and $96.3 \%$, respectively. Cox regression analysis controlling for age, sex, comorbidities, ejection fraction, and medications proved CKD to be the strongest independent predictor of death (hazard ratio 10.5; 95\% CI 4.8-23.1; $\mathrm{p}=$ $0.0001)$. This risk was dependant on severity of CKD; a $10-\mathrm{ml} / \mathrm{min}$ reduction in creatinine clearance was associated with a $55 \%$ increase in hazard of death $(\mathrm{p}<0.0001)$. They concluded that in patients receiving an ICD for primary prevention of SD, CKD significantly reduced longterm survival. This poor prognosis may limit the impact of primary prevention ICD therapy in this patient population [77].

Robin et al. [85] reported that only 19 (3.2\%) dialysis patients received an ICD device among 585 ICD recipients. In their study, dialysis was strongly associated with appropriate ICD therapy for ventricular tacharrrhytmias (hazard ratio 2.3 ; 95\% CI 1.2-4.5), survival was also shorter in dialysis patients compared to nondialysis patients $(3.2 \pm 0.6$ vs. $7.4 \pm 0.5$ years; $\log$-rank $\mathrm{p}=0.009)$. Other studies also demonstrated survival disadvantage for dialysis patients who received ICD device [76, 77]. Contradictory reports also exist. Herzog et al. [86] showed that only $7.6 \%$ of resuscitated dialysis patients received an ICD device. The 1-, 2-, 3-, 4- and 5-year survival rates in the ICD group were $71,53,36,25$ and $22 \%$, respectively; in the non-ICD group, they were 49, 33, 23, 16 and $12 \%$ $(\mathrm{p}<0.0001)$. ICD implantation was independently associated with a $42 \%$ reduction in death risk (relative risk 0.58 , 95\% CI 0.50-0.66) even after adjusting for comorbid conditions and baseline characteristics of the patients. Although this study was retrospective observational in nature, it supports the use of ICDs in the secondary prevention of sudden cardiac death in dialysis patients. So one must be careful before tempting to speculate that ICD does not work in dialysis patients since none of these mentioned retrospective studies can adequately address whether ICD prolong life for dialysis patients. Clearly, well-controlled prospective studies are needed to highlight these issues. 


\section{Conclusion}

Sudden cardiac death is one of the single most important causes of mortality in dialysis patients. There are multiple and unique risk factors present for the development of SD in this patient population. Predictors of risk for ESRD-related SD are needed and further character- ization of the causal pathways of SD in the dialysis population can help identify patients at higher risk and determine targeted interventions to decrease the likelihood of $\mathrm{SD}$ in this population. Currently, more aggressive treatment of CAD, greater use of ACE-i/ARBs $\beta$-blockers, and ICDs show promise for decreasing the incidence of SD in ESRD.

\section{References}

1 Henry RM, Kostense PJ, Bos G, Dekker JM, Nijpels G, Heine RJ, Bouter LM, Stehouwer CD: Mild renal insufficiency is associated with increased cardiovascular mortality: the Hoorn Study. Kidney Int 2002;62:1402-1407.

2 US Renal Data System Annual Data Report Bethesta, National Institutes of Health $\mathrm{Na}$ tional Institute of Diabetes and Digestive and Kidney Diseases, 2005.

3 Herzog CA, Mangrum JM, Passman R: Sudden cardiac death and dialysis patients. Semin Dial 2008;21:300-307.

4 Ritz E, Strumpf C, Katz F, Wing AJ, Quellhorst E: Hypertension and cardiovascular risk factors in hemodialyzed diabetic patients. Hypertension 1985; 7:II118-II124.

5 Ganesh SK, Stack AG, Levin NW, HulbertShearon T, Port FK: Association of elevated serum $\mathrm{PO}(4), \mathrm{Ca} \times \mathrm{PO}(4)$ product, and parathyroid hormone with cardiac mortality risk in chronic hemodialysis patients. J Am Soc Nephrol 2001;12:2131-2138.

6 Furgeson SB, Chonchol: Beta-blockade in chronic dialysis patients. Semin Dial 2008; 21:43-48.

7 Karnik JA, Young BS, Lew NL, Herget M, Dubinsky C, Lazarus JM, Chertow GM: Cardiac arrest and sudden death in dialysis units. Kidney Int 2001;60:350-357.

8 Moss AH, Holley JL, Upton MB: Outcomes of cardiopulmonary resuscitation in dialysis patients. J Am Soc Nephrol 1992;3:12381243.

9 Ranpuria R, Hall M, Chan CT, Unruh M: Heart rate variability (HRV) in kidney failure: measurement and consequences of reduced HRV. Nephrol Dial Transplant 2008; 23:444-449.

10 Hayano J, Takahashi H, Toriyama T, Mukai S, Okada A, Sakata S, Yamada A, Ohte N, Kawahara $\mathrm{H}$ : Prognostic value of heart rate variability during long-term follow-up in chronic haemodialysis patients with endstage renal disease. Nephrol Dial Transplant 1999;14:1480-1488.

11 Wanner C, Krane V, März W, Olschewski M, Mann JF, Ruf G, Ritz E, German Diabetes and Dialysis Study Investigators: Atorvastatin in patients with type 2 diabetes mellitus undergoing hemodialysis. N Engl J Med 2005; 353:238-248.
12 Ritz E, Wanner C: The challenge of sudden death in dialysis patients. Clin J Am Soc Nephrol 2008;3:920-929.

13 Remppis A, Ritz E: Cardiac problems in the dialysis patient: beyond coronary disease. Semin Dial 2008;21:319-325.

14 Saragoça MA, Canziani ME, Cassiolato JL, Gil MA, Andrade JL, Draibe SA, Martinez EE: Left ventricular hypertrophy as a risk factor for arrhythmias in hemodialysis patients. J Cardiovasc Pharmacol 1991;17(suppl 2):S136-S138.

15 Parfrey PS, Foley RN, Harnett JD, Kent GM Murray DC, Barre PE: Outcome and risk factors for left ventricular disorders in chronic uraemia. Nephrol Dial Transplant 1996;11: 1277-1285.

16 Redaelli B, Cavalli A, Latini R: (No authors listed) Multicentre, cross-sectional study of ventricular arrhythmias in chronically haemodialysed patients: Gruppo Emodialisi e Patologie Cardiovasculari. Lancet 1988;ii: 305-309.

17 Tamura K, Tsuji H, Nishiue T, Tokunaga S, Yajima I, Higashi T, Iwasaka T: Determinants of ventricular arrhythmias in hemodialysis patients: evaluation of the effect of arrhythmogenic substrate and autonomic imbalance. Am J Nephrol 1998;18:280-284.

18 Chen PS, Chou CC, Tan AY, Zhou S, Fishbein MC, Hwang C, Karagueuzian HS, Lin SF: The mechanisms of atrial fibrillation. J Cardiovasc Electrophysiol 2006;17(suppl 3):S2S7.

19 Amann K, Breitbach M, Ritz E, Mall G: Myocyte/capillary mismatch in the heart of uremic patients. J Am Soc Nephrol 1998;9:10181022 .

20 Bleyer AJ, Hartman J, Brannon PC, ReevesDaniel A, Satko SG, Russell G: Characteristics of sudden death in hemodialysis patients. Kidney Int 2006;69:2268-2273.

21 Bleyer AJ, Russell GB, Satko SG: Sudden and cardiac death rates in hemodialysis patients. Kidney Int 1999;55:1553-1559.

22 Wu VC, Lin LY, Wu KD: QT interval dispersion in dialysis patients. Nephrology (Carlton) 2005;10:109-112

23 Lorincz I, Mátyus J, Zilahi Z, Kun C, Karányi Z, Kakuk G: QT dispersion in patients with end-stage renal failure and during hemodialysis. J Am Soc Nephrol 1999;10:1297-1302.
24 Morris ST, Galiatsou E, Stewart GA, Rodger RS, Jardine AG: QT dispersion before and after hemodialysis. J Am Soc Nephrol 1999;10: 160-163.

25 Ozdemir D, Mese T, Agin H, Calkavur S, Bak M: Impact of haemodialysis on QTc dispersion in children. Nephrology (Carlton) 2005; 10:119-123.

26 Beaubien ER, Pylypchuk GB, Akhtar J, Biem $\mathrm{HJ}$ : Value of corrected QT interval dispersion in identifying patients initiating dialysis at increased risk of total and cardiovascular mortality. Am J Kidney Dis 2002;39:834842

27 Gussak I, Gussak HM: Sudden cardiac death in nephrology: focus on acquired long QT syndrome. Nephrol Dial Transplant 2007;22: 12-14.

28 Genovesi S, Dossi C, Viganò MR, Galbiati E, Prolo F, Stella A, Stramba-Badiale M: Electrolyte concentration during haemodialysis and QT interval prolongation in uraemic patients. Europace 2008;10:771-777.

29 Miller RF, Haley MW, Littmann L: Long QT syndrome: first and fatal events provoked by hemodialysis. Pacing Clin Electrophysiol 2003;26:103-104.

30 Zoccali C, Mallamaci F, Parlongo S, Cutrupi S, Benedetto FA, Tripepi G, Bonanno G, Rapisarda F, Fatuzzo P, Seminara G, Cataliotti A, Stancanelli B, Malatino LS: Plasma norepinephrine predicts survival and incident cardiovascular events in patients with endstage renal disease. Circulation 2002;105: 1354-1359.

31 Packer M: Current role of beta-adrenergic blockers in the management of chronic heart failure. Am J Med 2001;110(suppl 7):81S$94 \mathrm{~S}$

32 Johansson M, Gao SA, Friberg P, Annerstedt $M$, Carlström J, Ivarsson T, Jensen G, Ljungman S, Mathillas O, Nielsen FD, Strömbom U: Baroreflex effectiveness index and baroreflex sensitivity predict all-cause mortality and sudden death in hypertensive patients with chronic renal failure. J Hypertens 2007; 25:163-168.

33 Ondocin PT, Narsipur SS: Influence of angiotensin converting enzyme inhibitor treatment on cardiac autonomic modulation in patients receiving haemodialysis. Nephrology (Carlton) 2006;11:497-501. 
34 Chan CT, Hanly P, Gabor J, Picton P, Pierratos A, Floras JS: Impact of nocturnal hemodialysis on the variability of heart rate and duration of hypoxemia during sleep. Kidney Int 2004;65:661-665.

35 de Lima JJ, Vieira ML, Lopes HF, Gruppi CJ, Medeiros CJ, Ianhez LE, Krieger EM: Blood pressure and the risk of complex arrhythmia in renal insufficiency, hemodialysis, and renal transplant patients. Am J Hypertens 1999;12:204-208.

36 Abe S, Yoshizawa M, Nakanishi N, Yazawa T, Yokota K, Honda M, Sloman G: Electrocardiographic abnormalities in patients receiving hemodialysis. Am Heart J 1996;131: 1137-1144.

37 Bozbas H, Atar I, Yildirir A, Ozgul A, Uyar M, Ozdemir N, Muderrisoglu H, Ozin B: Prevalence and predictors of arrhythmia in end stage renal disease patients on hemodialysis. Ren Fail 2007;29:331-339.

38 Fischer R, Dechend R, Gapelyuk A, Shagdarsuren E, Gruner K, Gruner A, Gratze P, Qadri F, Wellner M, Fiebeler A, Dietz R, Luft FC, Muller DN, Schirdewan A: Angiotensin II-induced sudden arrhythmic death and electrical remodeling. Am J Physiol Heart Circ Physiol 2007;293:H1242-H1253.

39 Raizada V, Skipper B, Luo W, Garza L, Hines CW, Harford AA, Zager PG, Griffith J, Raj D, Spalding CT: Renin-angiotensin polymorphisms and QTc interval prolongation in end-stage renal disease. Kidney Int 2005;68: 1186-1189.

40 Zannad F, Kessler M, Lehert P, Grünfeld JP, Thuilliez C, Leizorovicz A, Lechat P: Prevention of cardiovascular events in end-stage renal disease: results of a randomized trial of fosinopril and implications for future studies. Kidney Int 2006;70:1318-1324.

41 Takahashi A, Takase H, Toriyama T, Sugiura T, Kurita Y, Ueda R, Dohi Y: Candesartan, an angiotensin II type-1 receptor blocker, reduces cardiovascular events in patients on chronic haemodialysis - a randomized study. Nephrol Dial Transplant 2006;21: 2507-2512.

42 Parekh RS, Plantinga LC, Kao WH, Meoni LA, Jaar BG, Fink NE, Powe NR, Coresh J, Klag MJ: The association of sudden cardiac death with inflammation and other traditional risk factors. Kidney Int 2008;74:13351342.

43 US Renal Data System: USRDS 2002 Annual Data Report. Bethesda, National Institutes of Health, National Institute of Diabetes and Digestive and Kidney Diseases, 2002.

44 US Renal Data System: USRDS 2004 Annual Data Report. Bethesda, National Institutes of Health, National Institute of Diabetes and Digestive and Kidney Diseases, 2004.

45 US Renal Data System: USRDS 2006 Annual Data Report: Atlas of End-Stage Renal Disease in the United States. Bethesda, National Institutes of Health, National Institute of Diabetes and Digestive and Kidney Disease, 2006.
46 Sherman RA, Hwang ER, Bernholc AS, Eisinger RP: Variability in potassium removal by hemodialysis Am J Nephrol 1986;6:284288.

47 Santoro A, Mancini E, London G, Mercadal L, Fessy H, Perrone B, Cagnoli L, Grandi E, Severi S, Cavalcanti S: Patients with complex arrhythmias during and after haemodialysis suffer from different regimens of potassium removal. Nephrol Dial Transplant 2008;23. 1415-1421.

48 Cupisti A, Galetta F, Caprioli R, Morelli E, Tintori GC, Franzoni F, Lippi A, Meola M, Rindi P, Barsotti G: Potassium removal increases the QTc interval dispersion during hemodialysis. Nephron 1999;82:122-126.

49 Genovesi S, Rivera R, Fabbrini P, Dossi C, Bonforte G, Mircoli L, Ferrari AU, Stella A, Stramba-Badiale M: Dynamic QT interval analysis in uraemic patients receiving chronic haemodialysis. J Hypertens 2003;21:19211926.

50 Nakamura S, Ogata C, Aihara N, Sasaki O, Yoshihara $F$, Nakahama $H$, Inenaga $T$, Kimura G, Kawano Y: QTc dispersion in haemodialysis patients with cardiac complications. Nephrology (Carlton) 2005;10:113118.

51 Floccari F, Aloisi E, Nostro L, Caccamo C, Crisafulli A, Barillà A, Aloisi C, Romeo A Corica F, Ientile R, Frisina N, Buemi M: QTc interval and QTc dispersion during haemodiafiltration. Nephrology (Carlton) 2004;9: 335-340.

52 Herzog CA: Can we prevent sudden cardiac death in dialysis patients? Clin J Am Soc Nephrol 2007;2:410-412.

53 Rydén L, Ariniego R, Arnman K, Herlitz J, Hjalmarson A, Holmberg S, Reyes C, Smedgård P, Svedberg K, Vedin A, Waagstein F, Waldenström A, Wilhelmsson C, Wedel $\mathrm{H}$, Yamamoto M: A double-blind trial of metoprolol in acute myocardial infarction: effects on ventricular tachyarrhythmias. N Engl J Med 1983;17;308:614-618.

54 Azevedo ER, Kubo T, Mak S, Al-Hesayen A Schofield A, Allan R, Kelly S, Newton GE, Floras JS, Parker JD: Nonselective versus selective beta-adrenergic receptor blockade in congestive heart failure: differential effects on sympathetic activity. Circulation 2001; 104:2194-2199.

55 Piccirillo G, Luparini RL, Celli V, Moisè A, Lionetti M, Marigliano V, Cacciafesta M: Effects of carvedilol on heart rate and blood pressure variability in subjects with chronic heart failure. Am J Cardiol 2000;86:13921395, A6.

56 Mortara A, La Rovere MT, Pinna GD, Maestri R, Capomolla S, Cobelli F: Nonselective beta-adrenergic blocking agent, carvedilol, improves arterial baroflex gain and heart rate variability in patients with stable chronic heart failure. J Am Coll Cardiol 2000;36: 1612-1618.
57 Faber JE, Brody MJ: Neural contribution to renal hypertension following acute renal artery stenosis in conscious rats. Hypertension 1983;5:I155-I164.

58 Ye S, Ozgur B, Campese VM: Renal afferent impulses, the posterior hypothalamus, and hypertension in rats with chronic renal failure. Kidney Int 1997;51:722-727.

59 Hausberg M, Kosch M, Harmelink P, Barenbrock M, Hohage H, Kisters K, Dietl KH, Rahn KH: Sympathetic nerve activity in endstage renal disease. Circulation Circulation 2002;106:1974-1979.

$60 \mathrm{Xu} \mathrm{J}, \mathrm{Li}$ G, Wang P, Velazquez H, Yao X, Li Y, Wu Y, Peixoto A, Crowley S, Desir GV: Renalase is a novel, soluble monoamine oxidase that regulates cardiac function and blood pressure. J Clin Invest 2005;115:1275-1280.

61 Daugirdas JT: Pathophysiology of dialysis hypotension: an update. Am J Kidney Dis 2001;38(suppl 4):S11-17.

62 Hjalmarson A: Cardioprotection with betaadrenoceptor blockers: does lipophilicity matter? Basic Res Cardiol 2000;95(suppl 1): I41-I45.

63 Gehr TW, Tenero DM, Boyle DA, Qian Y, Sica DA, Shusterman NH: The pharmacokinetics of carvedilol and its metabolites after single and multiple dose oral administration in patients with hypertension and renal insufficiency. Eur J Clin Pharmacol 1999;55: 269-277.

64 Feuerstein GZ, Hamburger SA, Smith EF 3rd, Bril A, Ruffolo RR Jr: Myocardial protection with carvedilol. J Cardiovasc Pharmacol 1992;19(suppl 1):S138-S141.

65 Chonchol M, Benderly M, Goldbourt U: Beta-blockers for coronary heart disease in chronic kidney disease. Nephrol Dial Transplant 2008;23:2274-2279.

66 Pun PH, Lehrich RW, Smith SR, Middleton JP: Predictors of survival after cardiac arrest in outpatient hemodialysis clinics. Clin J Am Soc Nephrol 2007;2:491-500.

67 Cice G, Ferrara L, Di Benedetto A, Russo PE, Marinelli G, Pavese F, Iacono A: Dilated cardiomyopathy in dialysis patients - beneficial effects of carvedilol: a double-blind, placebo-controlled trial. J Am Coll Cardiol 2001; $37: 407-411$

68 Cice G, Ferrara L, D’Andrea A, D'Isa S, Di Benedetto A, Cittadini A, Russo PE, Golino P, Calabrò R: Carvedilol increases two-year survivalin dialysis patients with dilated cardiomyopathy: a prospective, placebo-controlled trial J Am Coll Cardiol 2003;41:14381444.

69 Kalaitzidis R, Bakris G: Should nephrologists use beta-blockers? A perspective Nephrol Dial Transplant 2009;24:701-702.

70 Efrati S, Zaidenstein R, Dishy V, Beberashvili I, Sharist M, Averbukh Z, Golik A, Weissgarten J: ACE inhibitors and survival of hemodialysis patients. Am J Kidney Dis 2002;40:1023-1029. 
$71 \mathrm{~K} / \mathrm{DOQI}$ Workgroup: K/DOQI clinical practice guidelines for cardiovascular disease in dialysis patients. Am J Kidney Dis 2005;45(suppl 3):S1-S153.

72 Lehrich RW, Pun PH, Tanenbaum ND, Smith SR, Middleton JP: Automated external defibrillators and survival from cardiac arrest in the outpatient hemodialysis clinic. J Am Soc Nephrol 2007; 18:312-320.

73 Antiarrhythmics versus Implantable Defibrillators (AVID) Investigators: A comparison of antiarrhythmic-drug therapy with implantable defibrillators in patients resuscitated from near-fatal ventricular arrhythmias. N Engl J Med 1997;337:1576-1583.

74 Hreybe H, Ezzeddine R, Bedi M, Barrington W, Bazaz R, Ganz LI, Jain S, Ngwu O, London B, Saba S: Renal insufficiency predicts the time to first appropriate defibrillator shock. Am Heart J 2006;151:852-856.

75 Bloom H, Heeke B, Leon A, Mera F, Delurgio D, Beshai J, Langberg J: Renal insufficiency and the risk of infection from pacemaker or defibrillator surgery. Pacing Clin Electrophysiol 2006;29:142-145.

76 Bardy GH, Lee KL, Mark DB, Poole JE, Packer DL, Boineau R, Domanski M, Troutman C, Anderson J, Johnson G, McNulty SE, Clapp-Channing N, Davidson-Ray LD, Fraulo ES, Fishbein DP, Luceri RM, Ip JH, Sudden Cardiac Death in Heart Failure Trial (SCD-HeFT) Investigators: Amiodarone or an implantable cardioverter-defibrillator for congestive heart failure. N Engl J Med 2005; 352:225-237.
77 Cuculich PS, Sánchez JM, Kerzner R, Greenberg SL, Sengupta J, Chen J, Faddis MN, Gleva MJ, Smith TW, Lindsay BD: Poor prognosis for patients with chronic kidney disease despite ICD therapy for the primary prevention of sudden death. Pacing Clin Electrophysiol 2007;30:207-213.

78 Moss AJ, Zareba W, Hall WJ, Klein H, Wilber DJ, Cannom DS, Daubert JP, Higgins SL, Brown MW, Andrews ML, Multicenter Automatic Defibrillator Implantation Trial II Investigators: Prophylactic implantation of a defibrillator in patients with myocardial infarction and reduced ejection fraction. $\mathrm{N}$ Engl J Med 2002;346:877-883.

79 Eckart RE, Gula LJ, Reynolds MR, Shry EA, Maisel WH: Mortality following defibrillator implantation in patients with renal insufficiency J Cardiovasc Electrophysiol 2006; 17: 940-943.

80 Wase A, Basit A, Nazir R, Jamal A, Shah S, Khan T, Mohiuddin I, White C, Saklayen M, McCullough PA: Impact of chronic kidney disease upon survival among implantable cardioverter-defibrillator recipients. J Interv Card Electrophysiol 2004;11:199-204.

81 Goldenberg I, Moss AJ, McNitt S, Zareba W, Andrews ML, Hall WJ, Greenberg H, Case RB; Multicenter Automatic Defibrillator Implantation Trial-II Investigators: Relations among renal function, risk of sudden cardiac death, and benefit of the implanted cardiac defibrillator in patients with ischemic left ventricular dysfunction Am J Cardiol 2006 98:485-490.
82 McCullough PA: Why is chronic kidney disease the 'spoiler' for cardiovascular outcomes? J Am Coll Cardiol 2003;41:725-728.

83 Dasgupta A, Montalvo J, Medendorp S, Lloyd-Jones DM, Ghossein C, Goldberger J, Passman R: Increased complication rates of cardiac rhythm management devices in ESRD patients. Am J Kidney Dis 2007;49: 656-663.

84 Amin MS, Fox AD, Kalahasty G, Shepard RK, Wood MA, Ellenbogen KA: Benefit of primary prevention implantable cardioverter-defibrillators in the setting of chronic kidney disease: a decision model analysis. J Cardiovasc Electrophysiol 2008;19:1275-1280.

85 Robin J, Weinberg K, Tiongson J, Carnethon M, Reddy M, Ciaccio C, Quadrini M, Hsu J, Fan J, Choi P, Kadish A, Goldberger J, Passman R: Renal dialysis as a risk factor for appropriate therapies and mortality in implantable cardioverter-defibrillator recipients. Heart Rhythm 2006;3:1196-1201.

86 Herzog CA, Li S, Weinhandl ED, Strief JW, Collins AJ, Gilbertson DT: Survival of dialysis patients after cardiac arrest and the impact of implantable cardioverter defibrillators. Kidney Int 2005;68:818-825. 